\title{
perifèria
}

Número 19 (2), Diciembre 2014

revistes.uab.cat/periferia

\section{Djunta-mon: migración caboverdiana y prácticas de ayuda mutua en la periferia de Lisboa}

\author{
Francisco José Cuberos Gallardo - Centro de Investigação e Estudos de \\ Sociologia / Instituto Universitário de Lisboa (CIES-IUL) ${ }^{1}$
}

DOI: http://dx.doi.org/10.5565/rev/periferia.436

\section{Resumen}

En su incorporación a la sociedad receptora, las poblaciones migrantes reproducen con frecuencia sistemas de ayuda mutua importados desde sus países de origen. El objetivo de este artículo es reflexionar sobre el proceso de adaptación de estas prácticas al contexto migratorio. Para ello se presenta el análisis del djunta-mon, un sistema de ayuda mutua originario de Cabo Verde que ha sido incorporado por los migrantes de este país a la periferia de Lisboa.

En la Cova da Moura, un humilde barrio de génesis ilegal, la práctica del djuntamon ha permitido al vecindario dar respuesta a múltiples problemas durante cuarenta años. A través de la descripción etnográfica, se propone un recorrido por las diferentes aplicaciones que este sistema ha recibido a lo largo del tiempo, atendiendo especialmente a la evolución de sus formas, funciones y significados.

Palabras clave: migración, cultura de origen, ayuda mutua, entreayuda, Cabo Verde, Lisboa, Portugal

\begin{abstract}
In their incorporation to the host society, migrant populations often reproduce mutual aid systems imported from their home countries. The aim of this article is to reflect on the process of adapting these practices to immigration context. This work presents the analysis of the djunta-mon, a mutual aid system from Cape Verde which has been adopted by migrants in the periphery of Lisbon.

In Cova da Moura, a humble neighborhood with an illegal origin, such practice has allowed its inhabitants to address multiple problems for forty years. With the help of ethnographic description, we propose a tour through the different applications that this system has received over time, specially attending to the evolution of their forms, functions and meanings.
\end{abstract}

Keywords: migration, culture of origin, mutual help, mutual aid, Cape Verde, Lisbon, Portugal

\footnotetext{
${ }^{1}$ Enviar correspondencia a: Francisco José Cuberos Gallardo francisco.jose.cuberos@iscte.pt
} 


\section{perifèria}

Número 19 (2), Diciembre 2014

revistes.uab.cat/periferia

\section{Introducción}

En este artículo se analiza cómo los migrantes caboverdianos reproducen en la periferia de Lisboa formas de ayuda mutua propias de su cultura de origen. Concretamente nos centramos en el djunta-mon, una institución de gran importancia en Cabo Verde que es recuperada y actualizada para hacer frente a nuevos problemas en el contexto migratorio. La importancia de esta práctica se ha hecho evidente en distintos barrios lisboetas, en los que ha sido utilizada tanto para entablar formas de asistencia recíproca entre particulares como para impulsar proyectos de interés colectivo. Mediante una actualización permanente de sus formas, funciones y significados, el djunta-mon ha llegado a jugar un papel determinante en el asociacionismo vecinal de barrios como Cova da Moura, donde se ubica el estudio de caso que se presenta. Se trata por tanto de un caso exitoso de adaptación a un entorno migratorio urbano de una tradición procedente del medio rural caboverdiano.

Djunta-mon es una expresión compuesta que en el criollo de Guinea Bissau y Cabo Verde equivale a "juntar las manos". En el archipiélago de Cabo Verde, y muy especialmente en la isla de Santiago, el djunta-mon constituye una forma de ayuda mutua consistente en la formación de grupos de familiares, amigos y/o vecinos que colaboran sucesivamente en los trabajos agrícolas necesarios en las tierras de cada uno de ellos. La lógica de esta tradición está directamente ligada a las particularidades meteorológicas de estas islas, y más específicamente a su régimen pluviométrico. La limitación de la etapa de lluvias a un plazo de tiempo muy corto provoca que las tareas agrícolas se concentren en pocas semanas y que, consecuentemente, surja la necesidad de disponer de una gran cantidad de mano de obra en momentos concretos. Mediante el djunta-mon, cada persona consigue recabar esa cantidad de trabajo en sus tierras, principalmente para la plantación, el desbroce y la cosecha, a cambio de prestar su propio esfuerzo para las mismas tareas en las tierras de sus vecinos. Esta institución ha resultado fundamental en las islas para el sostenimiento de una agricultura tradicional basada predominantemente en el cultivo de maíz y legumbres (Weeks 2013).

En el sistema de djunta-mon cada participante invita al resto a colaborar en el trabajo de sus tierras, asumiendo a cambio una doble responsabilidad: una 


\section{perifèria}

Número 19 (2), Diciembre 2014

revistes.uab.cat/periferia

inmediata, consistente en proporcionar comida y bebida a los invitados mientras dura la tarea; y otra diferida, en forma de compromiso de devolver a estos invitados la misma cantidad de trabajo cuando éstos la necesiten. Se observa en este sentido una lógica de reciprocidad equilibrada en los términos definidos por Sahlins (1965), donde a cambio de la prestación de un servicio se espera la devolución de un valor aproximado en un plazo de tiempo más o menos acotado.

Dentro del propio archipiélago caboverdiano, hace tiempo que el djunta-mon sobrepasó su origen rural y fue adaptado a nuevas necesidades propias de la vida urbana. En ciudades como Praia esta práctica ha sido registrada en barrios periféricos, donde han sido especialmente las mujeres quienes la han adecuado a su propia problemática. En estos contextos, según muestra Solomon (1992), el djunta-mon es aplicado sobre todo al trabajo doméstico, y asume la forma de una ayuda mutua organizada en tareas de cocina o cuidado de niños, así como en la prestación de artículos de primera necesidad -frigoríficos, utensilios de lavado, etc.y ofrecimiento de alimentos, agua o albergue.

El djunta-mon también parece haber viajado con aquellos caboverdianos que han optado por hacer su vida lejos de su tierra de origen. La diáspora caboverdiana, que actualmente integra aproximadamente a la mitad de la población nacida en las islas ${ }^{2}$, aparece como un escenario en el que esta práctica asume nuevos usos y nuevas formas. Así se constata en la periferia de Lisboa, adonde una vasta población caboverdiana comenzó a llegar durante los años setenta y coincidiendo con el proceso de descolonización portuguesa. En el barrio de Cova da Moura, ubicado en la municipalidad de Amadora, el sistema de djunta-mon ha sido empleado por los migrantes para hacer frente a muchas de las carencias que sufren. Mediante el recurso a esta práctica tradicional caboverdiana, los vecinos han logrado organizarse de manera eficaz para la realización de tareas colectivas y establecer formas de solidaridad que contribuyen a amortiguar sus condiciones materiales de vida y a reforzar un potente sentido de comunidad.

\footnotetext{
2 Según el Instituto das Comunidades de Cabo Verde, el número de caboverdianos residentes en el extranjero asciende a un total de 517.078 , mientras que la población residente en las islas está cifrada en 527.000 (2012).
} 


\section{perifèria}

Número 19 (2), Diciembre 2014

revistes.uab.cat/periferia

La reproducción del djunta-mon en Lisboa nos habla de la aplicación en el contexto migratorio de estructuras de entreayuda propias de la cultura de origen. Un fenómeno que, por lo demás, también ha sido observado en otros colectivos. Así, en sus trabajos sobre la migración boliviana a Buenos Aires, Susana Sassone ha registrado la reproducción de formas organizadas de ayuda mutua incorporadas desde el país de origen, incluyendo el ayni y el anticrético (Sassone 2014). Una práctica básicamente idéntica al ayni boliviano, la minga andina, ha sido documentada entre los migrantes ecuatorianos residentes en Sevilla (Cuberos 2012). El djunta-mon caboverdiano, por su parte, presenta claros paralelismos con el ayni y la minga. Todas estas instituciones presentan una estructura similar, consistiendo básicamente en la prestación de un trabajo no remunerado que es destinado a cubrir una necesidad del grupo o bien de alguno de sus miembros. $Y$ todas ellas reproducen una lógica basada en la reciprocidad, que refuerza la cohesión del grupo y beneficia a la comunidad en su conjunto.

La incorporación de estas prácticas al contexto de recepción aporta una información rica al debate sobre el papel de la cultura de origen en el proceso migratorio. Lejos de quedar reducida al espacio del folklore y la tradición, la cultura de origen demuestra seguir teniendo aplicaciones prácticas en la gestión de los problemas cotidianos en los nuevos lugares de residencia. En estas condiciones, la reproducción de dicha cultura pasa a ser una necesidad que entronca con las estrategias cotidianas de los grupos.

\section{Contextualización del trabajo}

Los datos presentados en este artículo se enmarcan dentro de un proyecto de investigación postdoctoral orientado a analizar de manera comparativa las culturas políticas y estrategias asociativas de distintos colectivos de inmigrantes en las ciudades de Sevilla y Lisboa ${ }^{3}$. En este texto presentamos datos preliminares correspondientes al caso de los caboverdianos en la capital portuguesa, un caso

\footnotetext{
3 "The role of immigrant associations in the integration process. Comparing POS and political cultures in the cities of Seville and Lisbon". Este proyecto recibe el apoyo de una beca Postdoctoral de la Fundação para a Ciência e a Tecnologia (FCT) de Portugal.
} 


\section{perifèria}

Número 19 (2), Diciembre 2014

revistes.uab.cat/periferia

cuyas particularidades deben ser tenidas en cuenta. Frente al patrón de inserción dispersa que ha caracterizado a la inmigración en España (Torres 2006), en Portugal los caboverdianos han tendido con frecuencia a conformar barrios altamente etnizados en los que son mayoría frente al resto de grupos. Estos barrios se concentran en la periferia de Lisboa, y especialmente en los concelhos de Amadora, Oeiras, Loures y Odivelas, donde estos inmigrantes encontraron hace cuatro décadas terrenos yermos que presentaban una relativa cercanía tanto a las fábricas que en aquel momento proveían de empleo como a las líneas ferroviarias que daban acceso a la ciudad de Lisboa. En zonas como la Cova da Moura, se fueron formando asentamientos improvisados que con el tiempo han devenido en barrios ilegales, infradotados y generalmente estigmatizados. Hoy este barrio, seriamente afectado por graves problemas urbanísticos, económicos y de integración social, continúa siendo habitado mayoritariamente por inmigrantes y descendientes de inmigrantes. Aproximadamente el sesenta por ciento de los siete mil vecinos de la Cova da Moura proceden de los llamados PALOP ${ }^{4}$ y mayoritariamente de las islas de Cabo Verde.

La Cova da Moura se ubica en la ciudad de Amadora, que según el censo oficial cuenta con 175.136 habitantes. Desde hace dos décadas, el ayuntamiento de esta ciudad ha llevado a cabo una intensa política de recualificación urbanística, que en la práctica ha supuesto el realojo de la mayor parte de la población inmigrante en grandes bloques de viviendas dispersos por distintos puntos de la ciudad. La elección del barrio de Cova da Moura se justifica precisamente por ser uno de los pocos que han resistido este proceso de realojo. A diferencia de la mayor parte de barrios de la zona, la Cova da Moura presenta básicamente su trazado urbano originario, con viviendas unifamiliares en las que hoy continúan viviendo los mismos inmigrantes que las levantaron. Este hecho tiene implicaciones importantes para nuestro trabajo, pues en la Cova da Moura encontramos hoy unas redes vecinales que conectan con los propios orígenes del barrio. Buena parte del

\footnotetext{
4 PALOP es el acrónimo de Países Africanos de Língua Oficial Portuguesa: Angola, Cabo Verde, Guinea Bissau, Mozambique y Santo Tomé y Príncipe.
} 


\section{perifèria}

Número 19 (2), Diciembre 2014

revistes.uab.cat/periferia

vecindario de este lugar tomó parte de su construcción y ha experimentado su historia en primera persona.

Tal y como refleja su nombre oficial -Alto da Cova da Moura- este barrio se destaca sobre una colina que se encastra entre las freguesias de Damaia y Buraca ${ }^{5}$, limitando al norte con la línea de tren Sintra-Lisboa y al sur con la autopista A37 que une Sintra y Buraca. En torno a un trazado característico de calles estrechas y mal asfaltadas, los vecinos de este enclave han levantado un barrio humilde que sólo mediante una dura lucha consiguió tener acceso a los servicios básicos de agua, luz y alcantarillado. Su origen informal y su condición irregular, unidos a una imagen negativa ligada al tráfico de drogas y la pequeña delincuencia, dotan a este barrio de una particular idiosincrasia que ha contribuido a su fama en el área metropolitana de Lisboa y en el conjunto del país. Dentro de la población del barrio destacan en número los caboverdianos y sus descendientes, pero existe también un número significativo de portugueses, así como importantes minorías de guineanos, santotomenses, angoleños y mozambiqueños. Más recientemente se ha incorporado una considerable población procedente de Europa del Este, si bien el barrio continúa siendo percibido, tanto desde dentro como desde fuera, como un enclave africano en Europa ${ }^{6}$. Los nombres de las calles, su decoración y el perfil de los comercios evocan permanentemente el origen caboverdiano de la mayor parte de sus vecinos. $Y$ es común que ellos mismos se refieran cariñosamente a su barrio como Ilha da Cova da Moura, integrándolo simbólicamente como una isla más en su archipiélago de origen.

\section{Métodos y técnicas}

El trabajo de campo ha sido desarrollado durante un total de ocho meses distribuidos entre 2013 y 2014. Para el abordaje de los datos primarios se ha optado por una metodología de base cualitativa, basada en la observación

\footnotetext{
${ }^{5}$ La Cova da Moura pertenece a la freguesía de Buraca. La freguesía representa el más bajo nivel del sistema administrativo portugués, justamente por debajo de las cámaras municipales (que equivalen a los ayuntamientos españoles).

${ }^{6}$ En España, el diario El País publicó en 2007 un reportaje sobre este barrio titulado "Cova da Moura: retratos del último gueto africano" (http://internacional.elpais.com/internacional/2007/03/23/actualidad/1174604401_850215.html)
} 


\section{perifèria}

Número 19 (2), Diciembre 2014

revistes.uab.cat/periferia

participante y en la realización de entrevistas en profundidad a los vecinos de la zona. La observación ha sido ordenada en base a un guión pautado, orientado a registrar formas de sociabilidad diferenciadas y distinguiendo las unidades de observación en función de los grados de formalidad de los distintos contextos. Los ejercicios de observación han sido llevados a cabo en tres tipos de situaciones: a) reuniones formales -principalmente en la Asociación Cultural Moinho da Juventude, centro neurálgico de la sociabilidad barrial de la que más adelante hablaremos-; b) reuniones informales -básicamente en encuentros entre amigos, meriendas, etc.-; y c) eventos públicos y acontecimientos extraordinarios -celebraciones, actos oficiales, etc.-. En todos estos contextos se ha atendido a los modos de sociabilidad entre los vecinos, prestando especial atención a las redes de relaciones que los unen, al uso de los espacios y a la construcción discursiva de fronteras dentro y fuera del barrio.

Las entrevistas han tenido como objetivo la captación de la experiencia de los vecinos a través de sus propios discursos. Han sido aplicados dos guiones de entrevista diferentes: uno más corto, usado para registrar la experiencia y las opiniones de una veintena de vecinos, incluyendo a hombres y mujeres de diversas nacionalidades -caboverdianos, portugueses, angoleños y guineanos-, y con diferentes niveles de antigüedad en el barrio; y uno segundo más extenso, que hemos reservado a un número pequeño de informantes clave que han jugado un papel especialmente destacado en la vida asociativa del barrio y en la organización de las prácticas de ayuda mutua. Este segundo guión se ha orientado a reconstruir en detalle la trayectoria de estas personas y a profundizar a través de sus palabras en la descripción de la historia del barrio.

Finalmente, la información recogida sobre el terreno ha sido complementada con la consulta sistemática de documentación bibliográfica y material audiovisual. Se ha llevado a cabo una revisión en profundidad del material editado sobre inmigración caboverdiana en Portugal, y especialmente de los trabajos ya realizados en este barrio y su entorno. Paralelamente, nos hemos apoyado en la consulta de fotografías producidas por los propios vecinos y asociaciones del barrio, así como de 


\section{perifèria}

Número 19 (2), Diciembre 2014

revistes.uab.cat/periferia

numerosas noticias aparecidas en medios de comunicación -prensa y televisión- y algunos vídeos y documentales de especial interés ${ }^{7}$.

A continuación dedicamos un apartado a perfilar los conceptos básicos que sustentan este trabajo. Posteriormente exponemos los datos recabados en esta investigación, agrupándolos en dos bloques. El primero de ellos se dedica a contextualizar los orígenes de la presencia caboverdiana en Lisboa y su evolución en el tiempo. El segundo se centra en el análisis del djunta-mon, repasando sus principales aplicaciones en el barrio de Cova da Moura.

\section{El lugar de la cultura de origen en el contexto migratorio}

En este trabajo interpretamos la migración como un proceso que, en la medida en que obliga a un grupo humano a abandonar su universo cultural de origen y a tomar contacto con otros grupos, espacios y situaciones, abre una oportunidad inmejorable para el estudio de las funciones adaptativas de la identidad (Comas y Pujadas 1991: 35). La entrada en un nuevo contexto determina la necesidad de recodificar la vida social, incluyendo aquí desde el propio espacio físico que se habita hasta las relaciones de las que se toma parte y los valores que se reproduce. En este proceso, la cultura de origen provee al migrante de un punto de apoyo: una materia prima que, en función del contexto, pasa a ser rearticulada y combinada con nuevos referentes. Sin embargo, este proceso de recreación de la cultura de origen ha sido valorado de muy diferentes formas por distintos autores.

Durante la primera mitad del siglo $X X$, los estudiosos de las migraciones proyectaron una valoración negativa sobre la reproducción de la cultura de origen por parte de los migrantes. Ésta fue interpretada generalmente como cultura disfuncional, y su reproducción en el seno de la sociedad receptora era vista como un lastre que retardaba la modernización de los migrantes y dificultaba su integración en la nueva sociedad. Subyace aquí la enorme influencia de los postulados de la Escuela de Chicago, y muy especialmente de la obra El campesino polaco (2004) de Thomas y Znaniecki, donde la migración aparece caracterizada

\footnotetext{
7 Destacan en este punto los documentales Ilha da Cova da Moura y Kola San Jon é festa di Kau Berdi del realizador Rui Simões.
} 


\section{perifèria}

Número 19 (2), Diciembre 2014

revistes.uab.cat/periferia

como un proceso desorganizador. Se afirmaba que la incorporación a la nueva sociedad tenía un efecto de desestructuración en las normas, los valores y los referentes culturales de los inmigrantes. En estas condiciones de anomia, parecía razonable esperar que los inmigrantes avanzasen hacia una progresiva asimilación cultural con la sociedad receptora y, consecuentemente, hacia una ruptura definitiva con su propia cultura de origen.

Posteriormente, el desarrollo de nuevas investigaciones fue demostrando que, a pesar de las previsiones de los teóricos chicaguenses, los grupos inmigrantes se esfuerzan por mantener y reproducir su propia cultura (Pujadas 1993:43). En este sentido, la obra de Glazer y Moyniham (1979) marca un punto de inflexión al cuestionar abiertamente la idea del melting pot y demostrar que en Nueva York los grupos étnicos minoritarios planteaban formas coherentes de resistencia cultural a la presión asimilacionsita de los WASP (Hutchinson y Smith 1996: 133). Desde esta perspectiva, la cultura de origen de estas personas ya no aparece como un survival disfuncional, sino como un recurso que permite a los inmigrantes articular respuestas eficientes a sus nuevos problemas. $Y$ la migración no es interpretada como un trauma que necesariamente desestructura la cultura de origen de estos inmigrantes, sino más bien como un proceso que les obliga a re-articular esa cultura y adaptarla al nuevo contexto.

Lejos de haber sido resuelto, el debate sobre el lugar que corresponde a las culturas de origen de los migrantes continúa siendo hoy objeto de controversia. Recientemente, autores como Sartori (2001) o Azurmendi (2005) han afirmado ver en esas culturas de origen un obstáculo para el proceso de integración de los inmigrantes en las sociedades receptoras. Desde una concepción esencialista de estas culturas, les son atribuidos rasgos supuestamente incompatibles con las normas de la sociedad receptora e incluso con los propios valores democráticos. En este discurso el inmigrante aparece como el portador de una diferencia cultural inintegrable (Álvarez 2002) cuya disolución es requisito indispensable para la convivencia. Consecuentemente, los defensores de esta lectura muestran una honda desconfianza hacia las propuestas multiculturales y apuestan decididamente por la asimilación cultural de los inmigrantes. 


\section{perifèria}

Número 19 (2), Diciembre 2014

revistes.uab.cat/periferia

Otros autores, sin embargo, han visto en las culturas de origen de los inmigrantes un recurso que puede incidir positivamente en el proceso de integración. Los trabajos de Martín (1990; Martín y Pujadas 1999), Veredas (1999) o Morell (2005) han ilustrado la importancia de esta cultura compartida como factor de cohesión que articula las estrategias de integración de los inmigrantes. Frente a un entorno receptor que determina la necesidad de enfrentar nuevos desafíos, las culturas propias pasan a ser consideradas como recursos que vertebran formas eficaces de actuación sobre los problemas.

Es ésta la perspectiva que asumimos en este trabajo. Consideramos que la cultura de origen provee a los inmigrantes de unos recursos que, a través de su rearticulación en la sociedad receptora, pueden contribuir a mejorar las condiciones de integración de los grupos. En este sentido, el djunta-mon es considerado como un recurso valioso por cuanto conecta las estrategias de los vecinos de la Cova da Moura con saberes y relaciones adquiridos con carácter previo a su llegada a Portugal (Pujadas 1993:38). A través de este sistema los vecinos actualizan dichos saberes y relaciones y los rearticulan para hacer frente a sus nuevos problemas. El djunta-mon refleja una experiencia histórica común y unos códigos compartidos, y provee a los vecinos del barrio de un marco de significados desde el que interpretar su realidad actual (Hall 1995). Es la familiaridad de esos códigos la que posibilita formas de interacción ajustadas a las necesidades e intereses de estas personas. A través de las estructuras, valores y normas asociados a esta práctica tradicional el vecindario consigue dar respuestas coherentes y eficaces a los problemas y necesidades de su vida cotidiana.

Esta forma de afrontar el análisis del djunta-mon se basa en una concepción dinámica y no esencialista de la identidad cultural de los pueblos. No perseguimos determinar la forma pura de esta práctica ni clasificar sus funciones esenciales. Por el contrario, partimos de que el djunta-mon, como el resto de rasgos y marcadores culturales de un grupo, es susceptible de experimentar transformaciones como resultado de su adaptación a los cambios del entorno, sin que ello implique una pérdida de la identidad cultural (Barth 1976). Por este motivo, al abordar esta institución tradicional optamos por distinguir claramente entre sus formas, sus funciones y sus significados (Moreno 2002). Partimos de que las discontinuidades en una de estas dimensiones no tienen por qué entrañar cambios análogos en las 


\section{perifèria}

Número 19 (2), Diciembre 2014

revistes.uab.cat/periferia

demás. Nuestra hipótesis es que, en la adaptación al contexto migratorio, esta práctica se mantiene en la medida en que conserva funciones y significados que son importantes para el grupo, si bien a nivel formal se observe una evolución en el tiempo coherente con la variabilidad del contexto.

\section{La migración de caboverdianos a Lisboa: orígenes, evolución y características básicas}

La población caboverdiana en Portugal está hoy cifrada en 42.857 personas por el Servicio de Extranjeros y Fronteras (SEF 2013), órgano oficial encargado de registrar y controlar la presencia de extranjeros en territorio portugués. Si nos atenemos a este dato, dicha población aparece como la tercera minoría inmigrante del país, sólo superada por los nacionales de Brasil y de Ucrania. Por otra parte, la longevidad de la presencia caboverdiana en suelo luso ha permitido la consolidación en la actualidad de segundas, terceras e incluso cuartas generaciones de descendientes de caboverdianos. El volumen total de toda esta población de origen caboverdiano fue estimado en 2008 en torno a las ochenta mil personas, incluyendo en este cálculo a los ya nacionalizados y a los indocumentados (Batalha $2008)^{8}$. Hablamos por tanto de una minoría de enorme importancia en Portugal, que se concentra muy especialmente en el área metropolitana de la capital, y cuya presencia entronca con la historia de unas islas indisolublemente ligadas a la migración internacional.

La fuerte tradición migratoria en el archipiélago caboverdiano puede ser constatada ya en los siglos XVII y XVIII. En esta etapa, y a raíz de la desertización provocada por la incorporación de un inadecuado modelo agrícola por parte de agricultores procedentes del Alentejo, Cabo Verde muestra una sistemática tendencia a la expulsión de grandes contingentes de población. La escasa pluviosidad en la zona, la pobreza de los suelos y las fuertes desigualdades generadas por las estructuras coloniales portuguesas están en la base de modelo socioeconómico que expulsa

\footnotetext{
${ }^{8}$ El criterio jurídico de reconocimiento de la nacionalidad portuguesa es el ius sanguinis desde la reforma de la Ley de Nacionalidad en 1981. Desde entonces, el nacido de padres caboverdianos es caboverdiano pese a haber nacido en Portugal (Sousa, 2003).
} 


\section{perifèria}

Número 19 (2), Diciembre 2014

revistes.uab.cat/periferia

periódicamente a amplias capas de la población caboverdiana (Carita y Rosendo 141). La mayor parte de esta población se traslada a Guinea-Bissau, si bien otra buena parte emigrará a Angola, Mozambique, Senegal y Brasil.

La entrada en el siglo XX marca una diversificación de los flujos migratorios con origen en el archipiélago, que pasan a dirigirse mayoritariamente a Estados Unidos, y más tarde a Brasil y a Argentina, sosteniéndose mientras tanto la ya citada migración a las otras colonias portuguesas en África. Es en la segunda mitad de este siglo cuando los caboverdianos empiezan a migrar a Europa, primero a Escandinavia y Europa central -Francia, Luxemburgo-, y más tarde a Italia y Portugal. Desde fines de los años 60, la migración caboverdiana se concentra casi exclusivamente en Portugal, y muy especialmente en Lisboa y su área metropolitana. Hasta 1975 esta migración se encuadra aún dentro de un único espacio lusófono sometido al control del imperio portugués con sede en Lisboa. A partir de 1975, año en que Cabo Verde obtiene la independencia y su reconocimiento como Estado, los caboverdianos siguen trasladándose a la exmetrópoli, incluso con mayor intensidad que en los años precedentes (Carita y Rosendo 142).

La independencia de Cabo Verde nos permite también marcar una división analítica entre dos corrientes migratorias diferenciadas con destino en Lisboa. Durante los últimos años del período colonial (1968-1974) se observa un primer flujo de caboverdianos directamente estimulado desde la metrópoli. El Estado portugués busca con esta movilidad solventar su propia carencia de mano de obra, en unos momentos en que buena parte de los jóvenes portugueses ha emigrado a Centroeuropa o bien se encuentra luchando en las guerras coloniales en África. Por otra parte, la fuerte sequía que en estos momentos padece Cabo Verde y el cese de las tradicionales contrataciones de caboverdianos en las plantaciones de Santo Tomé y Príncipe también predisponen a esta población a considerar la opción migratoria (Carita y Rosendo 1993, Batalha 2008, Gois 2008, Marques y Santos 2008). En este primer flujo abundan los cuadros técnicos forjados en la administración colonial, siendo igualmente considerable la presencia de estudiantes que se trasladan a Lisboa a mejorar su formación. Estas personas alcanzan un éxito relativo en su experiencia en Portugal, y en todo caso experimentan una mejor 


\section{perifèria}

Número 19 (2), Diciembre 2014

revistes.uab.cat/periferia

integración que los inmigrantes caboverdianos llegados después de la independencia (Carita y Rosendo 1993, Batalha 2008, Sardinha 2004).

Una vez consumada la caída del régimen dictatorial en 1974, Portugal contempla la aceleración de un proceso de descolonización que se traduce en la llegada al país de nuevos e importantes contingentes migratorios. De un lado, la antigua metrópoli se ve obligada a acoger a un número de entre quinientos mil y ochocientos mil portugueses retornados en apenas seis años. Estas personas, procedentes en su mayoría de Angola y, en menor medida, de Guinea, Mozambique, Cabo Verde y Santo Tomé, tienen que abandonar precipitadamente el continente africano e iniciar una nueva vida en Portugal (Pires et al. 1987, Rocha-Trindade 1995). Paralelamente, se inicia en Cabo Verde una importante migración laboral de población no-portuguesa negra y mulata, que alcanza cifras especialmente destacadas en el período 1974-1981. Este segundo grupo de inmigrantes caboverdianos presenta unas características claramente diferenciadas respecto a los integrantes del primer flujo pre-independencia. Hablamos ahora de trabajadores poco cualificados, cuya inserción se desarrolla en condiciones de extrema precariedad laboral y residencial. Es esta población la que muestra una marcada tendencia a establecerse de manera concentrada en la periferia del Área Metropolitana de Lisboa, un rasgo que obedece a la confluencia simultánea de varios factores. En primer lugar, coincide en estas fechas el despegue de una incipiente industria en la zona que demanda una alta cantidad de mano de obra. Esta demanda, que en una primera etapa se había nutrido de portugueses procedentes del medio rural, encuentra ahora en los caboverdianos una fuerza de trabajo numerosa y más barata. En segundo lugar, la periferia ofrece un amplio espacio de terrenos vacíos, y en su mayor parte abandonados, que permiten a los caboverdianos instalarse con una inversión mínima de capital.

Es así como miles de inmigrantes caboverdianos se instalan en los municipios del extrarradio lisboeta, principalmente a lo largo de la antigua carretera militar que circunda la ciudad -la conocida Estrada Militar- y en torno a los principales nodos de transporte. La Cova da Moura ofrece un emplazamiento privilegiado, con un acceso directo a las líneas ferroviarias que conectan con la capital. Esta colina, que se encuadra en su mayor parte dentro de una finca de titularidad privada, se encuentra a comienzos de los setenta en estado de semi-abandono y presenta por 


\section{perifèria}

Número 19 (2), Diciembre 2014

revistes.uab.cat/periferia

tanto unas condiciones idóneas para la instalación de los nuevos vecinos. El vecindario de la Cova da Moura va creciendo a partir de 1974 mediante la ocupación ilegal de terrenos, en un proceso que en sus primeros momentos cuenta con el beneplácito de las autoridades locales (Malherios y Mendes 2007), pero que pronto favorece una asociación simbólica entre la población inmigrante y un medio físico y social degradado, lo cual ha marcado decisivamente la percepción social de este barrio.

Desde esta primera fase, y durante veinte años, la población caboverdiana sigue creciendo en Amadora, y surtiendo de mano de obra tanto el programa de reestructuración económica del Distrito de Lisboa en los ochenta (Sardinha 2009: 107-108), como el fuerte crecimiento de la construcción civil en torno a la Expo'98 (Machado 1999: 58). A lo largo de este período la Cova da Moura va consolidando su condición de barrio africano, y va albergando en su seno unos elevados niveles de pobreza y marginación social, que a su vez motivan el desarrollo de una problemática de creciente complejidad. Será precisamente la dureza de esta situación, y la escasez de recursos para hacerle frente, la que exija de los vecinos de este barrio la forja de unas densas redes de apoyo mutuo, basadas en fuertes lazos vecinales con un alto componente de solidaridad (Malheiros y Mendes 2007: 197).

Los orígenes de la Cova da Moura reflejan un proceso muy particular de configuración espacial, en el que un colectivo específico, el de los inmigrantes caboverdianos, desarrolla un ejercicio de significación y diferenciación del territorio mediante su apropiación, delimitación y definición funcional (Garcés 2006: 6). La construcción física del barrio se ve trenzada desde su origen con la historia de estos inmigrantes, que van dotando a estas tierras abandonadas de un principio de sentido, habitando el espacio antes espacio vacío y convirtiéndolo así en un lugar propio (Augé 2002).

\section{La práctica del djunta-mon en el barrio de Cova da Moura}

El proceso de inserción residencial de estos inmigrantes va a tener consecuencias decisivas en sus redes de sociabilidad. Tal y como ya fue observado por Pujadas entre los andaluces que llegaban al barrio de Bonavista, en Tarragona, la dureza del contexto de recepción hace que para estas personas organizarse y ser solidarias 


\section{perifèria}

Número 19 (2), Diciembre 2014

revistes.uab.cat/periferia

aparezca como requisito indispensable para seguir existiendo como comunidad (Pujadas 1990: 315, Comas y Pujadas 1991: 38). La necesidad de limpiar los terrenos, construir las casas, ordenar las calles y obtener servicios básicos empuja a estos inmigrantes a entablar formas organizadas de solidaridad entre ellos. Así, los relatos de los vecinos sitúan las primeras aplicaciones del djunta-mon durante la propia construcción de las viviendas del barrio.

En estos primeros años el barrio fue habitado mediante la construcción de barracas, que sólo con el transcurrir del tiempo fueron sustituidas progresivamente por viviendas de mejor calidad. Al llegar a la zona, los inmigrantes pioneros encontraron como primer problema la necesidad de dotarse de un refugio estable en terrenos vacíos y carentes de las más elementales infraestructuras urbanísticas. Es para la construcción de estas barracas que los vecinos hacen uso del djunta-mon por primera vez en el nuevo contexto.

Cuando llegué al barrio aquí no había casas, no había nada: sólo barracas de madera. Para hacer las casas, ayudaban los vecinos. Usted hablaba con los colegas para hacerla. (João Lucio)

Según aparece reflejado en los relatos de los informantes, el grueso de las tareas propias de la construcción de la barraca era desarrollado por los miembros del grupo doméstico, en un trabajo duro en el que todos cooperaban. Los materiales, a menudo de madera, eran adquiridos en una serrería cercana, o bien rescatados de algún vertedero del entorno. Los varones cabeza de familia ejercían como jefes de obra, y las mujeres y los niños cooperaban fundamentalmente en la búsqueda y transporte de materiales. La construcción de la barraca podía demorarse varias semanas, teniendo en cuenta la dificultad de esta tarea y que sólo podía dedicarse a ella el poco tiempo libre que los inmigrantes tenían tras sus largas jornadas laborales. De hecho, son frecuentes en los relatos las alusiones a la construcción de estas barracas durante la noche. El djunta-mon era aplicado en aquellas fases de la construcción que, como la colocación del techo, exigían una realización rápida y por tanto una mayor cantidad de mano obra. El recurso a esta práctica permitía a los inmigrantes avanzar en tiempo la obra de su barraca gracias a la ayuda de los vecinos, a los que se devolvía el favor con una aportación de trabajo similar. 


\section{perifèria}

Número 19 (2), Diciembre 2014

revistes.uab.cat/periferia

La aplicación del djunta-mon a la construcción de viviendas es costumbre extendida en Cabo Verde. Es frecuente en estas islas que la gente lleve a cabo la construcción de su propia casa, apoyándose en vecinos y amigos para la realización de las tareas más penosas. En este sentido, lo que se observa en la Cova da Moura es un trasplante directo de las antiguas reglas de solidaridad entre particulares, que son reproducidas de forma exacta para reforzar nuevas redes de entreayuda y cohesión (Comas y Pujadas 1991: 53). Ahora bien, con el transcurso del tiempo, la propia evolución del barrio, de sus problemas y de las redes vecinales que lo atraviesan va provocando que esta práctica de ayuda mutua incorpore variaciones en sus formas, funciones y significados.

El proceso de construcción de las viviendas está en la base de una densa red de relaciones entre los caboverdianos de la Cova da Moura. Esta población va desarrollando un fuerte sentimiento de comunidad, que de un lado se apoya en un sustrato étnico compartido y de otro en la necesidad de unir fuerzas para afrontar problemas comunes. Entre esos problemas, pronto ocupa un lugar destacado la carencia de abastecimiento básico de agua, luz y alcantarillado. Para poder acceder a estos servicios los vecinos se ven en la necesidad de organizarse conjuntamente y desarrollar acciones sistemáticas de reivindicación ante el ayuntamiento de Amadora. Pronto comienzan a reunirse entre ellos y a debatir soluciones posibles. Es así como una parte importante del barrio, en su mayoría caboverdiana, advierte la necesidad de constituir una asociación.

Al principio, cuando estábamos en lucha por el agua, la gente no estaba directamente por hacer una asociación. Aquí existía una asociación de vecinos, que se preocupaba sobre todo de ordenar las calles y esas cosas. Nuestra lucha quedó un poco dificultada dentro de aquella asociación. Y me dí cuenta de que aquello no estaba funcionando. (Adele)

Ante la dificultad de canalizar sus demandas a través de la asociación de vecinos existente, una parte del vecindario opta por formalizar la Associação Cultural Moinho da Juventude en 1987. Esta organización, integrada mayoritariamente por inmigrantes, asume desde su origen un fuerte discurso de reivindicación de la identidad cultural caboverdiana. Este discurso incluye una promoción activa de la práctica del djunta-mon, que es presentado ya como un marcador de la identidad 


\section{perifèria}

Número 19 (2), Diciembre 2014

revistes.uab.cat/periferia

caboverdiana y como una herramienta valiosa para los vecinos del barrio. Así, la propia asociación va organizando periódicamente jornadas de movilización que reciben el nombre de djunta-mon. En estas jornadas los vecinos participan de concentraciones, colaboran en recogidas de firmas o secundan otro tipo de iniciativas, generalmente orientadas a reforzar sus reivindicaciones de servicios básicos para el barrio. Si se utiliza el nombre de djunta-mon para designar estas movilizaciones es porque la participación en ellas es concebida como una prestación colectiva de trabajo voluntario en favor de la comunidad. Observamos ya una variación formal en la estructura de esta práctica de entreayuda: en estos casos la prestación del trabajo ya no tiene lugar entre particulares, sino que es centralizado por una entidad -la asociación- que representa a la comunidad en su conjunto. Asimismo es la asociación la que asume en estas ocasiones las obligaciones propias del djunta-mon, incluyendo el ofrecimiento de comida y bebida, generalmente en forma de almuerzos comunitarios para los participantes en las luchas. Se observa así una interesante actualización de esta práctica, que incluye una creciente formalización de sus estructuras y una renovada centralidad de la idea del barrio en tanto comunidad.

No obstante, el sistema de djunta-mon aún va a presentar nuevas aplicaciones en la Cova da Moura. Merece la pena detenerse en una aplicación concreta, que ha ganado gran popularidad durante los últimos años, y que aparece como una respuesta del vecindario frente a los ya citados planes de recualificación urbanística del barrio.

A partir del año 1993, las administraciones públicas van a promover la aplicación de diversos planes de intervención y transformación urbana en la periferia de Lisboa. El primero de ellos será el Programa Especial de Realojamento (PER) ${ }^{9}$, auspiciado por los ayuntamientos de la zona, y cuyo objetivo prioritario es la erradicación de los barrios de barracas. Este plan promueve la concesión de apoyo financiero para la construcción, adquisición o arrendamiento de viviendas destinadas a realojar a las numerosas familias que en los años noventa aún viven en barracas. Desde esta aplicación pionera del PER, y especialmente durante los últimos diez años, se

\footnotetext{
${ }^{9}$ Decreto-Lei no.163/93 de 7 de Maio.
} 


\section{perifèria}

Número 19 (2), Diciembre 2014

revistes.uab.cat/periferia

observa un renovado interés institucional por el desarrollo de nuevas intervenciones urbanísticas que apuntan directamente a la Cova da Moura. Es el caso del Proyecto Urban II de las freguesías Damaia y Buraca, que se marca como objetivo una transformación en profundidad del perfil urbano y social del barrio en base a cuatro objetivos: 1) recualificar el ambiente urbano y valorizar el espacio público; 2) integrar a la población africana; 3) revitalizar el ambiente social; y 4) valorizar el contexto socio-educativo de la población juvenil (Malheiros y Mendes 2007: 210). En el año 2005, y con unos objetivos similares, el gobierno portugués lanza un tercer plan de intervención llamado Bairros Críticos $^{10}$. Este plan se centra en tres barrios considerados especialmente problemáticos: Cova da Moura (Amadora), Lagarteiro (Porto) y Vale da Amoreira (Moita).

Los vecinos de la Cova da Moura van a mostrar una actitud ambivalente hacia estos planes de intervención en el barrio. Si de un lado reciben con esperanza la posibilidad de mejorar sus condiciones materiales de vida, de otro temen tener que marcharse a otro lugar, perdiendo así sus casas y sus relaciones con los vecinos. La mayor parte de ellos, incluyendo a los dirigentes de la asociación Moinho da Juventude, se muestran escépticos respecto a las motivaciones reales de las administraciones patrocinadoras de estos programas. Todos son conscientes del proceso de revalorización experimentado por estos terrenos, y sospechan que tras las propuestas de realojo subyace realmente un interés especulativo.

Estigmatizaron mucho el barrio desde 2002, porque había un plan para hacer aquí: arrasar el barrio. (...) El plan que hicieron, que fue un arquitecto el que lo hizo, un urbanista, en 2002. Y era echar abajo el ochenta por ciento del barrio, y sólo quedaba el veinte por ciento. Y ya tenían ese plan, sólo que lo hicieron tan mal que nadie cayó en que estamos en una colina, e hicieron un plan como si el barrio fuera todo plano. (...) [Pero] Era así: nosotros teníamos que salir y después vendrían aquí personas con más dinero. (Adele)

Como se puede observar, buena parte de los vecinos temen que tras el supuesto interés de las administraciones por su situación se esconda en realidad un proceso

\footnotetext{
${ }^{10}$ Barrios Críticos.
} 


\section{perifèria}

Número 19 (2), Diciembre 2014

revistes.uab.cat/periferia

de gentrificación urbanística que les perjudique. En consecuencia, han desarrollado una estrategia de autoorganización articulada sobre dos líneas de trabajo: una primera, consistente en buscar la interlocución con las autoridades y el máximo apoyo exterior a través de la asociación Moinho da Juventude. $Y$ una segunda, orientada a combatir la desvalorización del barrio mediante la mejora de su imagen material y simbólica. Es en este punto donde se observa una nueva aplicación del djunta-mon. A través de esta institución, la asociación va a fomentar la realización de trabajos de mejora en el barrio mediante el esfuerzo voluntario de los propios vecinos.

Estas tareas consisten fundamentalmente en intervenciones a nivel de infraestructuras, orientadas a la mejora funcional y estética de las instalaciones públicas. Así, una de las principales tareas es el arreglo del asfaltado de las calles. Mediante el trabajo en djunta-mon, los más jóvenes activistas de la asociación consiguen organizarse para realizar esta tarea en diferentes puntos. La asociación, que hoy se encuentra consolidada y maneja considerables fondos económicos obtenidos principalmente mediante el acceso a subvenciones y la captación de donaciones solidarias, provee de la materia prima -cemento, grava, herramientas, etc.- y se encarga de visibilizar estos trabajos como aportaciones a la comunidad. El mismo sistema ha sido usado para pintar numerosas calles del barrio -a menudo decorándolas con grafitis reivindicativos que aluden tanto a la identidad del barrio como al origen caboverdiano de sus vecinos-, para arreglar tramos de conducciones de agua y luz, para restituir señales informativas e incluso para dotar a las calles de carteles que las identifican con nombres caboverdianos. De esta forma, y en respuesta a lo que es interpretado como una presión especulativa contraria a los intereses del barrio, el djunta-mon es rescatado para frenar su desvalorización y reforzar así la posición de los vecinos en la negociación con las autoridades. El djunta-mon asume de este modo una función esencial de reivindicación del control legítimo sobre este lugar, y consagra su doble significación de marcador de la identidad étnica caboverdiana y de la identidad barrial de la Cova da Moura.

\section{Conclusiones}

A través de varios ejemplos hemos constatado la persistencia del djunta-mon caboverdiano en el extrarradio de la ciudad de Lisboa. A lo largo de cuarenta años, 


\section{perifèria}

Número 19 (2), Diciembre 2014

revistes.uab.cat/periferia

esta práctica tradicional ha sido periódicamente actualizada para dar respuesta a los problemas de los vecinos inmigrantes y de sus descendientes. Transcurrido este tiempo, y teniendo en cuenta la importancia que hoy sigue teniendo el djunta-mon en la vida social de la Cova da Moura, podemos afirmar que esta práctica es una muestra del potencial adaptativo de la cultura de origen en el contexto migratorio.

Debe notarse que la continuidad en el tiempo de esta práctica de ayuda mutua no significa que ésta se haya mantenido estable en sus formas, funciones y significados. La evolución de la vida en el barrio ha ido planteando una serie muy diversa de retos, ante los cuales el djunta-mon ha sido reconstruido en formas cambiantes. Así, y a nivel formal, se observa una mayor institucionalización, que aumenta en paralelo a la consolidación de la asociación Moinho da Juventude y a su nuevo protagonismo. Si en la construcción de las primeras barracas el djunta-mon movilizaba una prestación de trabajo entre particulares, tanto en las luchas por los servicios básicos como en las recientes intervenciones de mejora urbanísitica aparece ya un sujeto colectivo, el barrio, que encarna a la comunidad en su conjunto y que centraliza el trabajo voluntario.

Paralelamente podemos señalar cambios acontecidos en las funciones cubiertas por esta práctica. En este sentido, más que a una sustitución de funciones asistimos a una superposición de nuevas funciones que se suman a las originarias. El djuntamon ha permitido, durante todo este tiempo, recabar grandes cantidades de trabajo para la ejecución de tareas que así lo precisaban. Pero además de ésta, el djunta-mon ha ido asumiendo nuevas funciones de gran importancia material y simbólica. En primer lugar, esta costumbre ha logrado involucrar a un alto número de vecinos en la gestión de los problemas del barrio, haciéndoles conocedores de sus problemas y partícipes de su solución. En segundo lugar, ha favorecido el sostenimiento de densas redes de sociabilidad entre los vecinos y la consolidación de formas de convivencia provechosas. Por último, el djunta-mon ha contribuido de forma crucial a la dignificación del vecindario y de su cultura, convirtiendo esa cultura en un eje de resistencia a la estigmatización.

Finalmente, y además de haber sido integrado como marcador característico de la vida social en este barrio, el significado del djunta-mon continúa apareciendo sistemáticamente ligado a la cultura de origen de los migrantes. Al practicarlo, 


\section{perifèria}

Número 19 (2), Diciembre 2014

revistes.uab.cat/periferia

estas personas imprimen nuevas formas a algo que continúan asociando con el entorno cultural del que proceden. En este sentido el djunta-mon, al igual que la propia identidad caboverdiana, no debe ser pensado como una reiteración incesante, sino más bien como "lo mismo que cambia" (Gilroy 1994). Su importancia para los vecinos no radica en su fidelidad a la tradición, sino en su versatilidad y su eficacia en el presente. Su pervivencia en Lisboa nos habla, más que de un retorno a las raíces de la comunidad caboverdiana, de una aceptación de sus derroteros comunes (Hall 2003: 18). Cabe esperar por tanto que, en la medida en que los vecinos de Cova da Moura sigan sintiéndose como una comunidad, el djunta-mon caboverdiano siga jugando un importante papel en la periferia de Lisboa.

\section{Bibliografía}

Álvarez, Ignasi (2002). "La construcción del inintegrable cultural", en Lucas, Javier de y Torres, F. (eds.) Inmigrantes: ¿cómo los tenemos? Algunos desafíos y (malas) respuestas. Madrid: Talasa Ediciones, pp. 168-195.

Augé, Marc (2002). Los no lugares. Espacios del anonimato. Barcelona: Gedisa.

AUTOR (AÑO)

Azurmendi, Mikel (2005). "Diez tesis sobre el multiculturalismo". Cuadernos de Pensamiento Político FAES, 8: 97-111.

Barth, Fredrik (1976). Los grupos étnicos y sus fronteras: la organización social de las diferencias culturales. México: Fondo de Cultura Económica.

Batalha, Luís (2008). "Cabo-verdianos em Portugal: "comunidade" e identidade", en Góis, Pedro (org.): Comunidade(s) cabo-verdiana(s): as múltiplas faces da imigração cabo-verdiana. Lisboa: ACIDI, pp. 25-36.

Carita, Cristina y Rosendo, V.N. (1993). "Associativismo cabo-verdiano em Portugal. Estudo de caso da Associação Cabo-verdiana em Lisboa". Sociologia. Problemas e práticas, 13: 135-152.

Comas, Dolors y Pujadas, J.J. (1991). "Familias migrantes: reproducción de la identidad y del sentimiento de pertenencia". Papers, 36: 33-56. 


\section{perifèria}

Número 19 (2), Diciembre 2014

revistes.uab.cat/periferia

Cuberos, Francisco José (2012). Relaciones interétnicas y participación democrática. Estrategias asociativas de los inmigrantes latinoamericanos residentes en Sevilla. Tesis doctoral. Universidad de Sevilla, Departamento de Antropología Social.

Garcés, Alejandro (2006). "Configuraciones espaciales de lo inmigrante: usos y apropiaciones de la ciudad". Papeles del CEIC, 20: 1-34 .

Gilroy, Paul (1994). The Black Atlantic: Modernity and Double Consciousness. Londres: Verso.

Glazer, Nathan y Moynihan, D.P. (1979). Beyond the melting pot: the negroes, puerto ricans, jews, italians and irish of New York City. Cambridge: Mass. MIT Press.

Góis, Pedro (2008). "Entre Janus e Hydra de Lerna: as múltiplas faces dos caboverdianos em Portugal", en Góis, Pedro (org.): Comunidade(s) cabo-verdiana(s): as múltiplas faces da imigração cabo-verdiana. Lisboa: ACIDI, pp. 9-36.

Hall, Stuart (1995). "New cultures for old", en Massey, Doreen and Jess, P. (eds.): A Place in the World? Places, Cultures and Globalization. Oxford: Oxford University Press, pp. 175-214.

Hall, Stuart (2003). "Introducción: ¿quién necesita «identidad»?", en Halll, Stuart y Du Gay, P. (eds.) Cuestiones de identidad cultural. Buenos Aires: Amorrortu, pp. 13-39.

Hutchinson, John y Smith, A.D. (1996). Ethnicity. Oxford: Oxford University Press. Machado, Fernando Luis (1999). "Imigrantes e estrutura social". Sociologia. Problemas e práticas, 29: 51-76.

Malheiros, Jorge Macaísta y Mendes, M. (Coords.) (2007). Espaços e expressões de conflito e tensão entre autóctones, minorias migrantes e não migrantes na área metropolitana de Lisboa. Lisboa: ACIDI.

Marques, María Margarida y Santos, R. (2008). "Política, Estado social e participação dos imigrantes em contexto suburbano: Oeiras durante a década de 1990", en Marques, María Margarida, Santos, R. y Leitão, J. (coords.): Migrações e 


\section{perifèria}

Número 19 (2), Diciembre 2014

revistes.uab.cat/periferia

participação social. As associações e a construção da cidadania em contexto de diversidade - $O$ caso de Oeiras. Lisboa: Fim de século, pp. 47-83.

Martín, Emma (1990). "Las asociaciones andaluzas en Cataluña y su funcion de reproducción de la identidad cultural", en Cucó, Josepa y Pujadas, J.J. (coords.): Identidades colectivas. Etnicidad y sociabilidad en la Península Ibérica. Valencia: Generalitat Valenciana, pp. 255-268.

Martín, Emma y Pujadas, J.J. (1999). "Movilización étnica, ciudadanía, transnacionalización y redefinición de fronteras: una introducción al tema", en Pujadas, Joan Josep, Martín, E. y Pais de Brito, J. (Coords.): Globalización, fronteras culturales y políticas y ciudadanía. Santiago de Compostela: Asociación Galega de Antropoloxía, pp. 7-16.

Morell, Antoni (2005). "El papel de las asociaciones de inmigrantes en la sociedad de acogida: cuestiones teóricas y evidencia empírica". Migraciones, 17: 111-142.

Moreno, Isidoro (2002). "La cultura andaluza en el comienzo del tercer milenio: balance y perspectivas". Revista de Estudios Regionales, 63: 137-157.

Pires, Rui Pena et al. (1987). Os Retornados. Um Estudo Sociográfico. Lisboa: Instituto de Estudos para o Desenvolvimento.

Pujadas, Joan Josep (1990). "Identidad etnica y asociacionismo en los barrios perifericos de Tarragona", en Cucó, Josepa y Pujadas, J.J. (coords.): Identidades colectivas. Etnicidad y sociabilidad en la Península Ibérica. Valencia: Generalitat Valenciana, pp. 307-323.

Pujadas, Joan Josep (1993). Etnicidad. Identidad cultural de los pueblos. Madrid: Eudema.

Rocha-Trindade, María Beatriz (1995). Sociologia das Migrações. Lisboa: Universidade Aberta.

Sahlins, Marshall (1963). "On the Sociology of Primite Exchange", en Gluckman, Max y Eggan, F. (comp.): The Relevance of Models for Social Anthropology. New York: F. Praeger, pp. 139-236.

Sardinha, João (2004). "O associativismo caboverdiano na Área Metropolitana de Lisboa e a inserção da comunidade caboverdiana na sociedade portuguesa". Atas 


\section{perifèria}

Número 19 (2), Diciembre 2014

revistes.uab.cat/periferia

do VIII Congresso Luso-Afro-Brasileiro de Ciências Sociais. Coimbra: Centro de Estudos Sociais.

Sardinha, João (2009). Immigrant Associations, Integration and Identity: Angolan, Brazilian and Eastern European Communities in Portugal. Amsterdam: Amsterdam University Press.

Sartori, Giovanni (2001). La sociedad multiétnica. Pluralismo, multiculturalismo y extranjeros. Madrid: Taurus.

Sassone, Susana (en prensa). "Paisajes étnicos en las periferias urbanas latinoamericanas: sobre la construcción y mutación de espacios residenciales en Buenos Aires". Actas del XIII Congreso de Antropología de la FAAEE: Periferias, fronteras y diálogos. Tarragona: Federación de Asociaciones de Antropología del Estado Español (FAAEE).

Servicio de Extranjeros y Fronteras (2013). Relatório de Imigração, Fronteiras e Asilo 2012. Oeiras: Serviço de Estrangeiros e Fronteras.

Simões, Rui (2010). Ilha da Cova da Moura [Documental] Real Ficção.

Simões, Rui (2012). Kola San Jon é festa di Kau Berdi [Documental] Real Ficção.

Solomon, Marla Jill (1992). "We can even feel that we are poor, but we have a strong and rich spirit": Learning from the Lives and Organization of the Women of Tira Chapéu, Cape Verde. Tesis doctoral. University of Massachusetts, School of Education.

Sousa, Nardi Abraão Dias de (2003). Imigração e cidadania local: associativismo imigrante e políticas públicas de Portugal. Praia: Instituto da Biblioteca Nacional e do Livro.

Thomas, William Isaac y Znaniecki, F. (2004). El campesino polaco en Europa y América. Madrid: Centro de Investigaciones Sociológicas, Boletín Oficial del Estado.

Torres, Francisco (2006). "La inserción urbana de los inmigrantes y su participación en la ciudad", en Simó, Carles y Torres, F. (Eds.) La participación de los inmigrantes en el ámbito local. Valencia: Tirant lo Blanch, pp. 91-132.

Veredas, Sonia (1999). "Procesos de construcción de identidad entre la población inmigrante". Papers, 57: 113-129. 


\section{perifèria}

Número 19 (2), Diciembre 2014

revistes.uab.cat/periferia

Weeks, Samuel (2013). "As you receive with one hand, so should you give with the other": the mutual-help practices of Cape Verdeans on the Lisbon periphery". Atas do colóquio internacional Cabo Verde e Guiné-Bissau: Percursos do saber e da ciência. Lisboa: Instituto de Investigação Científica Tropical. 